\title{
INCIDENCE OF AND RELATION BETWEEN THE COMMON COMPLICATIONS OF PREGNANCY AND DELIVERY
}

\author{
BY \\ C. J. ROBERTS, M.D., Ch.B., D.P.H. \\ Department of Social and Occupational Medicine, Welsh National School of Medicine
}

Much has been written about the influence of the common complications of pregnancy and delivery on the development of the infant and young child. The discovery of correlations between some of these complications and certain developmental and neurological abnormalities has led, among other things, to the establishment of an administrative procedure, the 'at risk' register, which aims at the early diagnosis of handicaps by following up infants who have experienced certain of the complications of pregnancy or birth. The significance of such correlations will depend, however, on the distribution of complications in the general population of pregnancies and on the extent to which they are inter-related.

In this paper data are presented which are derived from all single pregnancies in a small defined population. From them the incidence of the common complications of pregnancy and delivery and the frequency with which two or more of them occurred in the same pregnancy have been estimated. The implications of the frequent coexistence of complications are discussed in relation to the interpretation of reported associations between specific complications and neurological defects in infancy.

\section{MATERIAL AND MethodS}

Details about the population of pregnancies to which this paper relates have been given elsewhere (Roberts, 1968). Briefly, the sample consisted of all the single pregnancies which resulted in a live birth including premature births or births resulting from

TABLE I

DISTRIBUTION OF SAMPLE BY PARISH

\begin{tabular}{l|c|c|c}
\hline \multicolumn{1}{c|}{ Parish } & $\begin{array}{c}\text { Total No. of } \\
\text { Single } \\
\text { Pregnancies } \\
\text { July 1962- } \\
\text { March 1964 }\end{array}$ & $\begin{array}{c}\text { No. } \\
\text { Included } \\
\text { in Study }\end{array}$ & $\begin{array}{c}\text { No. in } \\
\text { Study as \% } \\
\text { of All Single } \\
\text { Pregnancies } \\
\text { in Area }\end{array}$ \\
\hline Dinas Powis & 209 & 187 & $89 \cdot 4$ \\
Rhoose & 118 & 104 & $88 \cdot 1$ \\
Pentyrch & 46 & 41 & $89 \cdot 1$ \\
\hline Total & 373 & 332 & $89 \cdot 0$ \\
\hline
\end{tabular}

labour induced before term, e.g., for bleeding, toxaemia, etc., in three adjacent parishes in the administrative county of Glamorgan from July 1962 to March 1964 (Table I). During that period there were 373 such pregnancies, of which 332 $(89 \%)$ are included in this study. Of the 41 mothers not included, 11 had moved away from the area and 30 were uncooperative.

In the study area special Developmental Assessment Clinics were held and information about the complications of pregnancy and delivery was collected by questioning the mothers at their first visits to the clinics, usually three to four weeks after delivery. These complications were defined as follows:

\section{Bleeding in Pregnancy}

Under this heading was included any vaginal blood loss reported by the mother as having taken place between the first missed period and the onset of labour, which, in the opinion of her medical attendant, necessitated bed rest or admission to hospital.

\section{TOXAEMIA}

The mothers were asked if there had been any trouble with blood pressure, swelling of the fingers or ankles, or abnormality of urine during pregnancy. Those replying in the affirmative were then asked if they had been admitted to hospital or had spent some time in bed because of the trouble. They were also asked if their doctors had given them any treatment to reduce the swelling or lower the blood pressure. Mothers stating that they had had a raised blood pressure or some swelling of the ankles and had been admitted to hospital or had been given treatment and told to go to bed by their doctors were classified as having had toxaemia.

\section{Anaemia}

The criterion chosen was a haemoglobin below $65 \%$ at some time during pregnancy. In the majority 
of cases the results of haemoglobin estimates were recorded on the maternity liaison cards or could be obtained from the forms returned to the local authority clinic from the haematology laboratory. In the few cases where difficulty was experienced in obtaining the results of the tests, the mothers were asked if the anaemia had been severe enough to need a course of injections.

\section{BIRTH HAZARDS}

This group was a heterogeneous one which included mothers who gave a history of birth asphyxia, forceps delivery, Caesarean section, exchange transfusion, or breech delivery.

\section{RESULTS}

Tables II and III show the incidence and interrelationship of the common complications of pregnancy and delivery. Tables IV, V, and VI show the relationship of these complications respectively to maternal age, parity, and social class.

TABLE II

INCIDENCE OF COMMON COMPLICATIONS IN 332 SINGLE PREGNANCIES

\begin{tabular}{l|c|c|c|c}
\hline Complications & $\begin{array}{c}\text { No. not } \\
\text { Associated } \\
\text { with Any } \\
\text { Other Com- } \\
\text { plications } \\
\text { Studied }\end{array}$ & $\begin{array}{c}\text { No. } \\
\text { Associated } \\
\text { with Other } \\
\text { Complica- } \\
\text { tions } \\
\text { Studied }\end{array}$ & $\begin{array}{c}\text { Total } \\
\text { No. of } \\
\text { Complica- } \\
\text { tions }\end{array}$ & $\begin{array}{c}\text { \%of } \\
\text { Whole } \\
\text { Sample }\end{array}$ \\
\hline $\begin{array}{l}\text { Bleeding } \\
\text { Toxaemia }\end{array}$ & 17 & 19 & 36 & 11 \\
$\begin{array}{l}\text { Prolonged } \\
\text { hyperemesis }\end{array}$ & 16 & 26 & 47 & 14 \\
$\begin{array}{l}\text { Anaemia } \\
\text { Birth hazards }\end{array}$ & 23 & 25 & 41 & 12 \\
\hline
\end{tabular}

TABLE III

INTER-RELATION BETWEEN COMPLICATIONS STUDIED (IN ARBITRARY ORDER OF PRIORITY) IN 332 SINGLE PREGNANCIES

\begin{tabular}{l|c|c|c|c|c}
\hline $\begin{array}{c}\text { Principal } \\
\begin{array}{c}\text { Complica- } \\
\text { tion }\end{array}\end{array}$ & Bleeding & Toxaemia & $\begin{array}{c}\text { Hypere- } \\
\text { mesis }\end{array}$ & Anaemia & $\begin{array}{c}\text { Birth } \\
\text { Hazards }\end{array}$ \\
\hline $\begin{array}{l}\text { Bleeding } \\
\text { Toxaemia }\end{array}$ & 17 & 4 & 5 & 3 & 7 \\
$\begin{array}{c}\text { Prolonged } \\
\text { hyperemesis }\end{array}$ & & 21 & 9 & 4 & 9 \\
$\begin{array}{c}\text { Anaemia } \\
\text { Birth hazards }\end{array}$ & & 16 & 1 & 10 \\
\hline
\end{tabular}

3 of the 332 mothers experienced 3 complications during the pregnancy as follows:

2 mothers had toxaemia plus hyperemesis plus birth hazards

1 mother had hyperemesis plus anaemia plus birth hazards

\section{BLEEDING}

Eleven per cent. (36) of the women gave a history of bleeding during pregnancy. Of these, about half (17) had an otherwise normal pregnancy, birth, and neonatal period, and half (19) had associated complications such as toxaemia (4), prolonged
TABLE IV

COMMON COMPLICATIONS OF PREGNANCY AND DELIVERY BY MATERNAL AGE

\begin{tabular}{l|c|c|c|c}
\hline \multirow{2}{*}{ Complications } & \multicolumn{3}{|c|}{ Percentage in Each Maternal Age Group } \\
\cline { 2 - 4 } & -25 & $25-29$ & $30+$ & Total \\
\hline Bleeding & $7 \cdot 8$ & 8.7 & 17.0 & 10.7 \\
Toxaemia & 11.3 & 16.5 & 14.9 & 14.3 \\
Prolonged & & & & \\
$\quad$ hyperemesis & 15.7 & 9.5 & 12.8 & 12.4 \\
Anaemia & 5.2 & 7.1 & 6.4 & 6.3 \\
Birth hazards & 17.4 & 16.5 & 11.7 & 15.5 \\
\hline
\end{tabular}

TABLE V

COMMON COMPLICATIONS OF PREGNANCY AND DELIVERY BY PARITY

\begin{tabular}{l|r|r|r|r}
\hline \multirow{2}{*}{ Complications } & \multicolumn{3}{|c}{ Percentage in Each Parity Group } \\
\cline { 2 - 3 } & \multicolumn{1}{c|}{1} & 2 & 3 or more & Total \\
\hline Bleeding & 6.6 & 15.0 & 12.5 & 10.7 \\
Toxaemia & 13.9 & 15.0 & 13.9 & 14.3 \\
Prolonged & & & \\
$\quad$ hyperemesis & 13.9 & 13.3 & 8.3 & 12.4 \\
Anaemia & 3.3 & 7.1 & 11.1 & 6.3 \\
Birth hazards & 17.9 & 11.5 & 16.7 & 15.5 \\
\hline
\end{tabular}

TABLE VI

COMMON COMPLICATIONS OF PREGNANCY AND DELIVERY BY SOCIAL CLASS

\begin{tabular}{l|c|c|c|c}
\hline \multirow{2}{*}{ Complications } & \multicolumn{3}{|c}{ Percentage in Each Social Class } \\
\cline { 2 - 4 } & I and II & III & IV and V & Total \\
\hline Bleeding & 12.4 & 10.4 & 7.8 & 10.7 \\
Toxaemia & 9.9 & 17.1 & 15.7 & 14.3 \\
Prolonged & & & & \\
$\quad$ hyperemesis & 14.9 & 9.2 & 17.7 & 12.4 \\
Anaemia & $4 \cdot 1$ & 6.1 & 11.7 & 6.3 \\
Birth hazards & 19.8 & 12.9 & 13.7 & 15.5 \\
\hline
\end{tabular}

hyperemesis (5), anaemia (3), and birth hazards (7).

Twenty-one of the 36 mothers bled during the first two months of their pregnancies and nine during the last month. Six mothers bled intermittently for several months, five of them during the first half of their pregnancies. The incidence of bleeding increased with increasing maternal age (Table IV) and was higher in the higher parity groups (Table V). The numbers were too small to permit separation of these two factors, but the association appeared to be much stronger with maternal age than with parity so the former is probably the more important. The incidence of bleeding was also appreciably greater among the higher social class groups (Table VI).

In the British Perinatal Mortality Survey (Butler and Bonham, 1963) $6 \%$ of women had bleeding in pregnancy, $3.8 \%$ before 28 weeks. The reported incidence of bleeding during the first six months in the present study was almost twice as great. This difference might possibly be due to a regional variation, but it is more likely to be due to differences in project methodology. In the Perinatal Mortality 
Survey bleeding was recorded from hospital or midwives' records, whereas in the present study a personal history was taken from the mother.

In the prospective study of 3,278 pregnant women by McDonald (1961), which was also based on personal histories, the incidence of bleeding in the pregnancies not terminating in abortion was $16 \cdot 1 \%$.

\section{TOXAEMIA}

Fourteen per cent. of the mothers had a history of toxaemia and more than half of these (26) also gave histories of other complications, such as bleeding (4), anaemia (4), prolonged hyperemesis (9), and birth hazards (9). There was no obvious association between toxaemia and either maternal age, parity or social class.

The incidence of toxaemia has been variously recorded as $4.1 \%$ (Browne and Browne, 1960), $4.8 \%$ (Lowe, 1961), 5.6\% (Gemmell, Logan, and Benjamin, 1954), and 8.6\% (Townsend, 1963). These results contrast sharply with those of the Perinatal Mortality Survey in which the incidence of mild toxaemia was $15.7 \%$, of moderate toxaemia $3.6 \%$, and of severe toxaemia $1.5 \%$. Even allowing for differences in definition, this suggests that the incidence of toxaemia is much higher than earlier studies had indicated. The incidence of $14 \%$ of toxaemia in the present study supports this suggestion.

\section{Prolonged Hyperemesis Gravidarum}

The proportion of mothers who had prolonged hyperemesis was $12 \%$ (41). More than two thirds (25) of these women had an associated obstetric complication such as bleeding (5), toxaemia (9), anaemia (1), and birth hazards (10). The incidence of hyperemesis in this study compares very well with the overall incidence of $14.7 \%$ reported by McDonald (1961).

Like toxaemia, hyperemesis was apparently unrelated to maternal age, parity or social class.

\section{Anaemia}

Six per cent. (21) of mothers had a haemoglobin of $65 \%$ or less and just over half of these (12) had associated complications. This is very similar to the incidence reported by the Perinatal Mortality Survey and by Davies and Shelley (1934), Boycott (1936), Adair, Dieckmann, and Grant (1936), and many others. The incidence of anaemia increased significantly with parity but not with maternal age, and was also related to social class (i.e., it was commoner among the poorer sections of the population).

\section{BirTh Hazards}

Sixteen per cent. (53) of the mothers gave a history of having experienced a birth hazard, and often of more than one.

More than half (30) of these women also gave a history of pregnancy complications such as bleeding (7), toxaemia (9), hyperemesis (10), and anaemia (4). Birth hazards were not significantly related to maternal age, parity or social class, although there was a suggestion that they might perhaps be a little commoner among the younger mothers and the higher social classes.

If birth complications do in fact present a foetal hazard, an incidence of $16 \%$ poses a considerable obstetric and paediatric problem, for one in six births will be 'at risk'.

\section{Discussion}

In this study the incidence of complications of pregnancy was in general rather higher than in earlier studies. There are two possible explanations for this. The first is that the incidence of abnormalities during the first six months of pregnancy is likely to be more accurately ascertained when there is a personal contact between the research worker and the mothers in the sample. This is very evident 8 from the study of McDonald (1961). It is certainly a mistake to assume that hospital records are neces sarily more reliable than the maternal histories about events which occurred during early pregnancy. The second possible explanation concerns the optimum time at which to record the obstetric history. A mother is most likely to be co-operative and most likely to give a reliable history a short while after the birth of her child. The mother who is questioned during the last trimester may be uncommunicative or guarded about events which took place in early pregnancy, and if she is questioned when her infant is 6 or more months old she will often have forgotten details of her pregnancy or confinement, or may feel that the enquiry is routine and unnecessary. This is particularly true of events which occurred during the first six months of pregnancy.

The findings of this study indicate that complications of pregnancy and birth very often co-exist. More than $50 \%$ of the women who gave histories of major complications of pregnancy and of birth hazards reported more than one of these complications and hazards. Investigations of the possible effects of one obstetric abnormality studied in isolation on the condition of the infant at birth or on his subsequent development can therefore lead to false conclusions even when strict sampling procedures are adopted.

Assessment of the role of birth hazards in the aetiology of minimal cerebral damage and of 
neuropsychiatric disorders is particularly difficult. It was found in the present investigation that $56 \%$ of mothers who had a complication of delivery also experienced complications during the pregnancy. Certain complications of pregnancy can directly influence the type of birth. For example, the findings of the Perinatal Mortality Survey showed that antepartum haemorrhage and preeclampsia raise the incidence of birth by Caesarean section, that unspecified antepartum haemorrhage and bleeding before 28 weeks is associated with a $50 \%$ rise in the incidence of forceps delivery, and that accidental antepartum haemorrhage is associated with a sevenfold increase in the percentage of assisted breech deliveries.

Clearly, it is unwise to study the influence on infant development of one complication of pregnancy in isolation since too many interdependent variables are involved, the action of which is incompletely understood.

Illingworth (1963) recognized this when he urged caution in the relating of anoxia at birth to developmental difficulties in infancy and childhood. Nevertheless, in disciplines which involve the study of behaviour disorders in childhood (e.g., paediatric audiology, child psychiatry, mental subnormality, and educational psychology) difficulties at birth are often regarded as the cause of hearing defects, linguistic disorders, specific learning difficulties, and behaviour problems, and the diagnosis of 'brain damage' is only too frequently applied to children who present with such symptoms and have a history of an abnormal birth. There is very little valid evidence to support these beliefs.

Finally, the present study has indicated that bleeding and toxaemia are constantly recurring themes in the study of obstetric complications. Not only are they of numerical importance $(20 \%$ of all pregnancies) but they are associated with $30 \%$ of all birth hazards and can also influence the type of birth the baby experiences.

\section{SuMmaRY}

This paper presents the results of a study of the distribution of the complications of pregnancy and delivery among 373 consecutive pregnancies in a defined population. Eighty-nine per cent. of the 373 mothers were included in the final analysis. The social class, parity, and maternal age struc- tures of the sample were known and there was a high level of patient co-operation.

Forty-two per cent. of the mothers experienced one or more of the following: bleeding, toxaemia, prolonged hyperemesis, severe anaemia or birth hazards. The results suggest that earlier studies have tended to underestimate the incidence of these complications.

More than half of the infants who had experienced difficulties at birth had also experienced one or more of the complications of pregnancy.

Bleeding and toxaemia were constantly recurring themes in the study of obstetric hazards. Not only were they of numerical importance $(20 \%$ of all pregnancies) but they were associated with $30 \%$ of all complications of delivery.

During the preparation of this paper the author was working on research projects financially supported by the Association for the Aid of Crippled Children. He wishes to express his gratitude for that support.

\section{REFERENCES}

Adair, F. L., Dieckmann, W. J., and Grant, K. (1936). Anemia in pregnancy. Amer. J. Obstet. Gynec., 32,560 .

BoycotT, J. A. (1936). Anaemia in pregnancy. Lancet, 1, 1165.

Browne, F. J., and Browne, J. C. (1960). Antenatal and Postnatal Care, 9th ed. Churchill, London.

Butler, N. R., and Bonham, D. G. (1963). Perinatal Mortality: The First Report of the 1958 British Perinatal Mortality Survey. Livingstone, Edinburgh.

Davies, D. T., and Shelley, U. (1934). Hypochromic anaemia and its relation to pregnancy. Lancet, 2, 1094.

Gemmell, A. A., Logan, W. P. D., and Benjamin, B. (1954). The incidence of toxaemia. J. Obstet. Gynaec. Brit. Emp., 61, 458.

ILLINGWORTH, R. S. (1963). The Development of the Infant and Young Child, Normal and Abnormal. 2nd ed. Livingstone, Edinburgh.

LOWE, C. R. (1961). Toxaemia and pre-pregnancy weight. J. Obstet. Gynaec. Brit. Cwlth., 68, 622.

McDonalD, A. D. (1961). Maternal health in early pregnancy and congenital defect. Final report on a prospective inquiry. Brit. J. prev. soc. Med., 15, 154.

ROBERTS, C. J. (1968). The Distribution of Neurological Signs in Early Infancy. 'Studies in Infancy' Clinics in Develop. Med. 27. Spastics International Publications.

TOWNSEND, S. L. (1963). The management of hypertension in pregnancy. In Modern Trends in Obstetrics 3, pp. 15-34. Ed. Kellar, R. J. Butterworths, London. 